\title{
Immunohistochemical expression of fibronectin and C5b-9 in the myocardium in cases of carbon monoxide poisoning
}

\author{
Tony Fracasso • Heidi Pfeiffer • Katarzyna Michaud • \\ Helga Köhler • Cristina Sauerland • Andreas Schmeling
}

Received: 22 March 2010 /Accepted: 26 August 2010/Published online: 17 September 2010

(C) Springer-Verlag 2010

\begin{abstract}
Even if there is clinical evidence that carbon monoxide poisoning determines cardiac damage, the literature on the cardiac pathomorphology in such cases is scarce. We investigated the immunohistochemical expression of two known markers of fresh cardiac damage, fibronectin and the terminal complement complex C5b-9, in both cardiac ventricles in 26 cases of $\mathrm{CO}$ intoxication (study group, 15 q, $11 \hat{\jmath}$, mean age 47 years, mean $\mathrm{COHb}$ level $65.9 \%$, min. $51 \%$, max. $85 \%$ ) compared to a group of 23 cases of hanging $(n=23,49,19 \hat{\text {, }}$, mean age 42 years) as well as to 25 cases of myocardial infarction $(n=25,13 \phi, 12 \hat{\jmath}$, mean age 64 years). Fresh cardiac damage was detected with the antibody fibronectin in cases of $\mathrm{CO}$ poisoning and was prevalently localised at the right ventricle.
\end{abstract}

Dedicated to Prof. Patrice Mangin on occasion of his 60th birthday

T. Fracasso $\cdot$ H. Pfeiffer $\cdot$ H. Köhler $\cdot$ A. Schmeling

Institute of Legal Medicine, University Hospital Münster,

Röntgenstr. 23,

48149 Münster, Germany

T. Fracasso $\cdot$ K. Michaud

University Center of Legal Medicine,

Rue Michel-Servet 1, 1211 Geneva, Rue de Bugnon 21,

1011 Lausanne, Switzerland

C. Sauerland

Institute of Medical Informatics and Biomathematics, University

Hospital Münster,

Domagkstr. 9,

48149 Münster, Germany

T. Fracasso $(\square)$

Centre Universitaire Romand de Médecine Légale, Hôpitaux

Universitaires de Genéve,

Rue Michel-Servet 1,

1211 Genève, Switzerland

e-mail: Tony.Fracasso@hcuge.ch
Keywords Right ventricle · Acute pulmonary hypertension - Right ventricular failure . Immunohistochemistry · Ischemic cardiac changes . Ischemia

\section{Introduction}

In legal medicine, $\mathrm{CO}$ intoxications represent one classical topic whose pathophysiology and pathology have repeatedly been discussed in the literature [1,2].

Even if the most described symptoms and signs related to $\mathrm{CO}$ intoxications refer to the toxic effects on the central nervous system [3], $\mathrm{CO}$ also determines substantial changes at cardiac level. CO-related cardiac damage is classically considered as the consequence of the formation of carboxyhemoglobin that decreases the amount of oxygen unloaded to the tissues leading to tissue hypoxia [4]. Moreover, a specific cardiotoxic effect has been discussed in relation to a disturbance of the mitochondrial activity [5].

From a functional point of view, a flattening or inversion of the $\mathrm{T}$ waves and a depression of the $\mathrm{R}-\mathrm{T}$ segment are the most common ECG changes $[6,7]$ and do not differ from other forms of hypoxia [8]. Satran et al. [9] more recently described the elevation of cardiac biomarkers or ECG changes indicating ischemia in $37 \%$ of 230 hospitalised cases of CO intoxication.

While there exists substantial evidence of functional cardiac changes in cases of $\mathrm{CO}$ intoxication, the literature on its pathomorphological patterns is scarce: Klebs [10] firstly described punctuate and diffuse haemorrhages at the pericardium and endocardium as well as at the tips of the papillary muscles in fatal $\mathrm{CO}$ intoxications. Ehrich et al. [11] reported haemorrhages in the myocardium of dogs killed 4 days after $\mathrm{CO}$ exposure: at autopsy, the animals displayed areas of necrosis, especially at the subendocardial 
regions. Similar results were later reported by Klavis and Schulz [12] in rats.

Also, medico-legal researchers have concentrated their attention on the topic of the cardiac changes in cases of $\mathrm{CO}$ intoxication: Marek and Piejko [13] reported congestion and extravasations in the stroma with discrete lesions of the muscle fibres at optical microscopy with H\&E. Fineschi et al. [14] did not detect any specific change in the myocardium in 26 forensic cases investigated with H\&E; only in three cases could small foci of coagulative myocytolysis be observed.

In this study, we wanted to evaluate whether fresh cardiac lesions are detectable at immunohistochemistry with the markers Fibronectin and C5b-9 in the cardiac musculature of both cardiac ventricles in a series of $\mathrm{CO}$ intoxications. In the attempt of better defining the nature of the possible cardiac damage, we further compared this group with a group of cases of hanging (group 2) in which global hypoxia occurs, as well as with myocardial infarctions (group 3) as typical example of ischemic lesions.

\section{Materials and methods}

Our study group consisted of 26 cases of CO intoxication (study group, 15 ,, $11 \delta$, mean age 47 years, mean $\mathrm{COHb}$ level $65.9 \%$, min. $51 \%$, max. $85 \%$ ). In 20 cases, the death was classified as accidental, in six cases as suicide. The second group consisted of cases of suicidal hanging $(n=23,4$ ㅇ, $19 \hat{\text {, }}$, mean age 42 years). The third group consisted of cases of myocardial infarction $(n=25,13 \uparrow, 12 \hat{\jmath}$, mean age 64 years). The diagnosis of heart infarction was made on the basis of the macroscopic findings and conventional histology with H\&E. In this group, there were no cases of isolated right ventricular infarction. The cases were collected at the Institute of Legal Medicine of the University Hospital in Münster and at the University Center of Legal Medicine in Lausanne and Geneva and retrospectively investigated. In each case, information about circumstances of death as well as autopsy record were available. The presence of signs of putrefaction at external examination was an exclusion criterion for this study. Similarly, cases with advanced autolysis were not included. An overview of the investigated cases is given in Tables 1, 2 and 3. Blood samples were taken from the heart. Carboxyhaemoglobin was measured by spectrophotometer according to Màehly's method [15]. Histological investigation of the heart, lung, liver, brain, kidney, pancreas and spleen, with haematoxylin and eosin performed according to standard medico-legal investigation [16]. In each case, immunohistochemical reactions with the antibodies fibronectin (Polyclonal Rabbit Anti-Human, DAKO Deutschland GmbH, Hamburg, Germany) and C5b9 (Monoclonal Mouse Anti-Human, DAKO Deutschland $\mathrm{GmbH}$, Hamburg, Germany) of at least one tissue slide from both cardiac ventricles (free wall of the right ventricle RV, anterior and/or posterior wall of the left ventricle LV) were prepared as described elsewhere [17, 18].

In 13 cases of $\mathrm{CO}$ intoxications (cases 14 to 26 in Table 1), heart samples were systematically collected from the free wall of the right ventricle, septum, anterior, lateral and posterior wall of the left ventricle.

A blind investigation of the slides was performed by two different observers with final consensual evaluation. The positive reactions were semiquantitatively classified as follows (Figs. 1, 2 and 3):

Group 0: negative reaction

Group 1: light reaction

Group 2: moderate reaction

Group 3: strong reaction

If more than one tissue slide from one ventricle was present, the average value rounded up to the nearest integer was considered.

The grade of necrosis in each ventricle for each antibody was compared to the corresponding value of the groups 2 and 3 (grade of necrosis RV Fibronectin study group versus grade of necrosis RV Fibronectin groups 2 and 3; grade of necrosis RV C5b-9 study group versus grade of necrosis RV C5b-9 groups 2 and 3; grade of necrosis LV Fibronectin study group versus grade of necrosis LV Fibronectin groups 2 and 3; grade of necrosis LV C5b-9 study group versus grade of necrosis RV C5b-9 groups 2 and 3).

The difference of the grade of the necrosis between right and left ventricle was calculated in each case $(\Delta=$ grade necrosis RV - grade necrosis LV) with both antibodies. A comparison of these differences between study group and groups 2 and 3 was performed. The groups 2 and 3 were finally compared to each other.

Statistical analyses were performed using SAS 9.2 (SAS Institute Inc., Cary, NC).

Fisher's exact test was used for all comparisons between the investigated groups. The result was considered significant in case of the two-sided $p<0.05$.

In the 13 cases of $\mathrm{CO}$ intoxications in which the heart specimens were collected systematically from the free wall of the right ventricle, the anterior, lateral and posterior wall of the left ventricle and the septum, the expression of two markers at the RV was compared to the expression at the different regions of the left ventricle. The different regions of the left ventricle were then compared to each other. For statistical analysis, the paired-sample Wilcoxon test was used.

\section{Results}

The immunohistochemical investigation of the right ventricle with the antibody fibronectin showed fresh necrosis in the vast majority of the $\mathrm{CO}$ intoxications; more precisely, light 
Table 1 Study group: CO intoxications

\begin{tabular}{|c|c|c|c|c|c|c|c|c|c|}
\hline ID & Sex & Age & $\mathrm{CO}-\mathrm{Hb}$ & RV Fibronectin & LV Fibronectin & $\Delta$ Fibronectin & RV C5b-9 & LV C5b-9 & $\Delta$ C5b-9 \\
\hline 1 & $\mathrm{~F}$ & 57 & $64 \%$ & 2 & 2 & 0 & 0 & 0 & 0 \\
\hline 2 & $\mathrm{~F}$ & 25 & $58 \%$ & 2 & 0 & 2 & 0 & 0 & 0 \\
\hline 3 & M & 38 & $73 \%$ & 3 & 2 & 1 & 0 & 0 & 0 \\
\hline 4 & $\mathrm{~F}$ & 47 & $55 \%$ & 2 & 0 & 2 & 0 & 0 & 0 \\
\hline 5 & $\mathrm{~F}$ & 90 & $57 \%$ & 1 & 0 & 1 & 0 & 0 & 0 \\
\hline 6 & $\mathrm{~F}$ & 25 & $54 \%$ & 3 & 3 & 0 & 0 & 0 & 0 \\
\hline 7 & $\mathrm{~F}$ & 17 & $70 \%$ & 2 & 0 & 2 & 0 & 0 & 0 \\
\hline 8 & $\mathrm{~F}$ & 2 & $66 \%$ & 2 & 2 & 0 & 0 & 0 & 0 \\
\hline 9 & $\mathrm{~F}$ & 85 & $62 \%$ & 0 & 0 & 0 & 0 & 0 & 0 \\
\hline 10 & M & 10 & $75 \%$ & 0 & 0 & 0 & 0 & 0 & 0 \\
\hline 11 & M & 75 & $61 \%$ & 1 & 1 & 0 & 0 & 0 & 0 \\
\hline 12 & $\mathrm{~F}$ & 87 & $63 \%$ & 2 & 0 & 2 & 0 & 0 & 0 \\
\hline 13 & $\mathrm{~F}$ & 75 & $62 \%$ & 2 & 0 & 2 & 0 & 0 & 0 \\
\hline 14 & M & 55 & $77 \%$ & 2 & 1 & 1 & 0 & 0 & 0 \\
\hline 15 & $\mathrm{~F}$ & 39 & $51 \%$ & 2 & 1 & 1 & 0 & 0 & 0 \\
\hline 16 & $\mathrm{M}$ & 74 & $59 \%$ & 1 & 1 & 0 & 0 & 0 & 0 \\
\hline 17 & $\mathrm{M}$ & 41 & $65 \%$ & 2 & 2 & 0 & 0 & 0 & 0 \\
\hline 18 & $\mathrm{M}$ & 46 & $81 \%$ & 3 & 1 & 2 & 0 & 0 & 0 \\
\hline 19 & M & 38 & $74 \%$ & 2 & 2 & 0 & 0 & 0 & 0 \\
\hline 20 & $\mathrm{M}$ & 73 & $65 \%$ & 2 & 1 & 1 & 0 & 0 & 0 \\
\hline 21 & M & 42 & $71 \%$ & 3 & 2 & 1 & 0 & 0 & 0 \\
\hline 22 & $\mathrm{M}$ & 42 & $58 \%$ & 2 & 1 & 1 & 0 & 0 & 0 \\
\hline 23 & $\mathrm{~F}$ & 34 & $72 \%$ & 3 & 2 & 1 & 0 & 0 & 0 \\
\hline 24 & $\mathrm{~F}$ & 57 & $74 \%$ & 2 & 1 & 1 & 0 & 0 & 0 \\
\hline 25 & $\mathrm{~F}$ & 41 & $61 \%$ & 3 & 2 & 1 & 0 & 0 & 0 \\
\hline 26 & F & 8 & $85 \%$ & 3 & 2 & 1 & 0 & 0 & 0 \\
\hline
\end{tabular}

$N=26(15 q, 11 \hat{\jmath}$, mean age 47 years $)$

necrosis was detected in three cases, moderate necrosis in 14 and strong necrosis in seven cases. In two cases, no necrosis could be detected. For what concerns the left ventricle, the occurrence of the necrosis was much lower with eight negative cases, eight cases of light necrosis, and nine of moderate necrosis. Strong necrosis was detected in this group at the left ventricle only once.

The reaction with the antibody C5b-9 was negative in all the investigated cases in both ventricles in the study group.

The comparison of the grade of necrosis in the right ventricle showed a prevalent expression of the antibody fibronectin in the study group compared to cases of hanging $(p<0.0323)$; in comparison with cases of myocardial infarction, the expression of this marker was similar. Fibronectin was more expressed at the RV in cases of myocardial infarction compared to hanging $(p<0.0493)$. The reaction with antibody against the terminal complement complex turned out negative at the RV both cases of $\mathrm{CO}$ intoxication and hanging. Positive reactions were observed in five cases at the RV in cases of heart infarction. The difference observed in comparison with the study group is statistically significant $(p<0.001)$.

The comparison of the grade of necrosis in the LV showed a prevalent involvement of this ventricle in both groups 2 and 3 compared to the study group, with fibronectin $(p<0.0350$ and $p<0.0001$ if compared with cases of hanging or heart infarctions, respectively). The comparison between the groups 2 and 3 showed a statistically significant prevalent involvement of the LV in cases of myocardial infarction $(p<0.001)$. The terminal complement complex C5b-9 was never detected in the $\mathrm{CO}$ and hanging groups at the left ventricle. Positive reactions occurred in 12 cases of myocardial infarction. The differences are statistically significant $(p<0.001)$.

The comparison of the difference of the grade of the necrosis between right and left ventricle with the antibody fibronectin ( $\Delta$ fibronectin) showed a statistically significant difference between the study group and both groups 2 and 3 
Table 2 Cases of heart infarction

\begin{tabular}{|c|c|c|c|c|c|c|c|c|}
\hline ID & Sex & Age & RV Fibronectin & LV Fibronectin & $\Delta$ Fibronectin & RV C5b-9 & LV C5b-9 & $\Delta$ C $5 b-9$ \\
\hline 1 & $\mathrm{~F}$ & 61 & 2 & 2 & 0 & 0 & 2 & -2 \\
\hline 2 & M & 62 & 2 & 3 & -1 & 0 & 3 & -3 \\
\hline 3 & M & 63 & 2 & 3 & -1 & 0 & 0 & 0 \\
\hline 4 & $\mathrm{~F}$ & 40 & 2 & 2 & 0 & 0 & 0 & 0 \\
\hline 5 & M & 78 & 2 & 3 & -1 & 1 & 2 & -1 \\
\hline 6 & $\mathrm{~F}$ & 81 & 2 & 3 & -1 & 2 & 2 & 0 \\
\hline 7 & M & 43 & 2 & 2 & 0 & 0 & 0 & 0 \\
\hline 8 & $\mathrm{~F}$ & 82 & 2 & 2 & 0 & 0 & 0 & 0 \\
\hline 9 & $\mathrm{~F}$ & 76 & 1 & 2 & -1 & 0 & 0 & 0 \\
\hline 10 & M & 67 & 2 & 3 & -1 & 0 & 2 & -2 \\
\hline 11 & M & 70 & 2 & 3 & -1 & 1 & 1 & 0 \\
\hline 12 & M & 66 & 2 & 2 & 0 & 0 & 0 & 0 \\
\hline 13 & $\mathrm{~F}$ & 53 & 2 & 2 & 0 & 0 & 0 & 0 \\
\hline 14 & $\mathrm{M}$ & 38 & 3 & 3 & 0 & 0 & 0 & 0 \\
\hline 15 & $\mathrm{~F}$ & 58 & 2 & 2 & 0 & 0 & 0 & 0 \\
\hline 16 & F & 87 & 2 & 0 & 2 & 0 & 2 & -2 \\
\hline 17 & F & 80 & 2 & 3 & -1 & 1 & 1 & 0 \\
\hline 18 & $\mathrm{~F}$ & 46 & 1 & 1 & 0 & 0 & 0 & 0 \\
\hline 19 & $\mathrm{M}$ & 41 & 3 & 3 & 0 & 0 & 2 & -2 \\
\hline 20 & $\mathrm{M}$ & 60 & 2 & 2 & 0 & 0 & 0 & 0 \\
\hline 21 & $\mathrm{~F}$ & 41 & 2 & 3 & -1 & 0 & 0 & 0 \\
\hline 22 & $\mathrm{M}$ & 47 & 1 & 3 & -2 & 0 & 2 & -2 \\
\hline 23 & $\mathrm{~F}$ & 88 & 2 & 3 & -1 & 0 & 1 & -1 \\
\hline 24 & $\mathrm{~F}$ & 82 & 2 & 2 & 0 & 0 & 0 & 0 \\
\hline 25 & $\mathrm{M}$ & 87 & 1 & 3 & -2 & 1 & 2 & -1 \\
\hline
\end{tabular}

$N=25,13 q, 12 \hat{\jmath}$, mean age 64 years

( $p<0.0001$ for both comparisons). The parameter $\Delta$ fibronectin was also differently distributed in the groups 2 and $3(p<0.0351)$.

In the 13 cases of $\mathrm{CO}$ intoxication with a systematic sampling from both ventricles, Fibronectin was significantly more expressed in the RV than in every region of the LV $(p<0.004)$. Moreover, the expression of this marker was similar at every region of the LV. These results are shown in Table 4.

\section{Discussion}

The antibodies used in our study are well-known markers of fresh cardiac ischemic lesions [19, 20]. Fibronectin diffuses into the ischemic cardiac cells already few minutes after the beginning of the ischemia [18]; the terminal complement complex C5b-9 is detectable at the surface of the damaged cardiac cells in form of membrane pores if ischemia has been survived for longer than 30-40 min [19]; it is considered a reliable marker of localised ischemic lesions and was shown not to react to global hypoxia [19]. On the contrary, fibronectin is appreciable for its rapid detectability after onset of the damage but is known to turn out positive also in cases of global hypoxia [21].

To evaluate whether in cases of $\mathrm{CO}$ intoxication-specific reaction patterns of these antibodies could be identified, we decided to compare our study group with cases of hanging in which global hypoxia occurs and with classical cases of acute ischemic myocardial damage.

In this study, we could demonstrate fresh cardiac damage with the antibody fibronectin, with different degrees of extension, in both ventricles in every investigated group. The immunohistochemical reaction with the terminal complement complex was instead negative in all the cases of $\mathrm{CO}$ intoxication and hanging. Positive reactions were observed in cases of myocardial infarction.

The different expression of these antibodies can be explained with the different survival time necessary after the onset of the damage to get positive results with the two markers: in cases of $\mathrm{CO}$ intoxications and hanging the time between beginning of the cardiac damage and death is 
Table 3 Cases of hanging

\begin{tabular}{|c|c|c|c|c|c|c|c|c|}
\hline ID & Sex & Age & RV Fibronectin & LV Fibronectin & $\Delta$ Fibronectin & RV C5b-9 & LV C5b-9 & $\Delta$ C5b-9 \\
\hline 1 & M & 42 & 2 & 2 & 0 & 0 & 0 & 0 \\
\hline 2 & M & 44 & 0 & 0 & 0 & 0 & 0 & 0 \\
\hline 3 & M & 56 & 1 & 2 & -1 & 0 & 0 & 0 \\
\hline 4 & $\mathrm{~F}$ & 46 & 0 & 0 & 0 & 0 & 0 & 0 \\
\hline 5 & M & 23 & 0 & 1 & -1 & 0 & 0 & 0 \\
\hline 6 & M & 54 & 2 & 2 & 0 & 0 & 0 & 0 \\
\hline 7 & $\mathrm{~F}$ & 55 & 2 & 2 & 0 & 0 & 0 & 0 \\
\hline 8 & $\mathrm{~F}$ & 43 & 2 & 2 & 0 & 0 & 0 & 0 \\
\hline 9 & M & 35 & 1 & 1 & 0 & 0 & 0 & 0 \\
\hline 10 & M & 56 & 2 & 2 & 0 & 0 & 0 & 0 \\
\hline 11 & M & 49 & 2 & 2 & 0 & 0 & 0 & 0 \\
\hline 12 & M & 20 & 0 & 1 & -1 & 0 & 0 & 0 \\
\hline 13 & M & 35 & 2 & 2 & 0 & 0 & 0 & 0 \\
\hline 14 & $\mathrm{M}$ & 21 & 0 & 0 & 0 & 0 & 0 & 0 \\
\hline 15 & $\mathrm{M}$ & 40 & 2 & 2 & 0 & 0 & 0 & 0 \\
\hline 16 & $\mathrm{M}$ & 41 & 2 & 2 & 0 & 0 & 0 & 0 \\
\hline 17 & $\mathrm{M}$ & 38 & 2 & 2 & 0 & 0 & 0 & 0 \\
\hline 18 & $\mathrm{M}$ & 31 & 2 & 2 & 0 & 0 & 0 & 0 \\
\hline 19 & $\mathrm{M}$ & 34 & 2 & 2 & 0 & 0 & 0 & 0 \\
\hline 20 & $\mathrm{M}$ & 56 & 2 & 2 & 0 & 0 & 0 & 0 \\
\hline 21 & $\mathrm{M}$ & 63 & 2 & 2 & 0 & 0 & 0 & 0 \\
\hline 22 & $\mathrm{~F}$ & 51 & 2 & 2 & 0 & 0 & 0 & 0 \\
\hline 23 & $\mathrm{M}$ & 33 & 1 & 2 & -1 & 0 & 0 & 0 \\
\hline
\end{tabular}

$N=23,4+, 19 \hat{\jmath}$, mean age 42 years

Fig. 1 CO intoxication (Table 1, case 13). a Fibronectin, RV, grade 2. b C5b-9, RV, grade 0 . c Fibronectin, LV, grade 0 . d C5b-9, LV, Grade $0 . \Delta$ Fibronectin $=2, \Delta$ C $5 b-9=0$
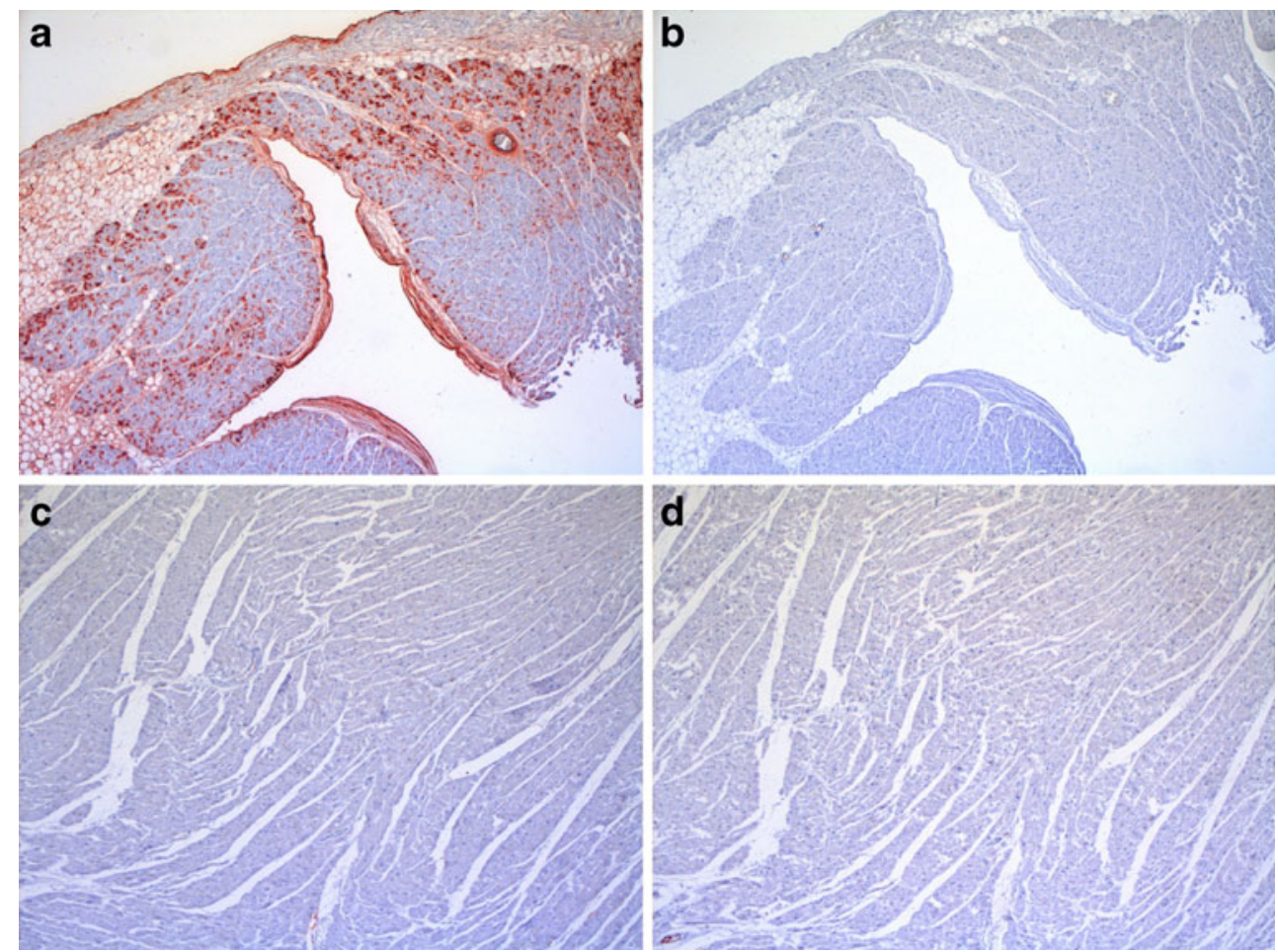
Fig. 2 Myocardial infarction (Table 2, case 10). a Fibronectin, $\mathrm{RV}$, grade 2. b C5b-9, RV, grade 0. c Fibronectin, LV, grade 3. d C5b-9, LV, Grade 2. $\Delta$ Fibronectin $=-1$, $\Delta \mathrm{C} 5 \mathrm{~b}-9=-2$
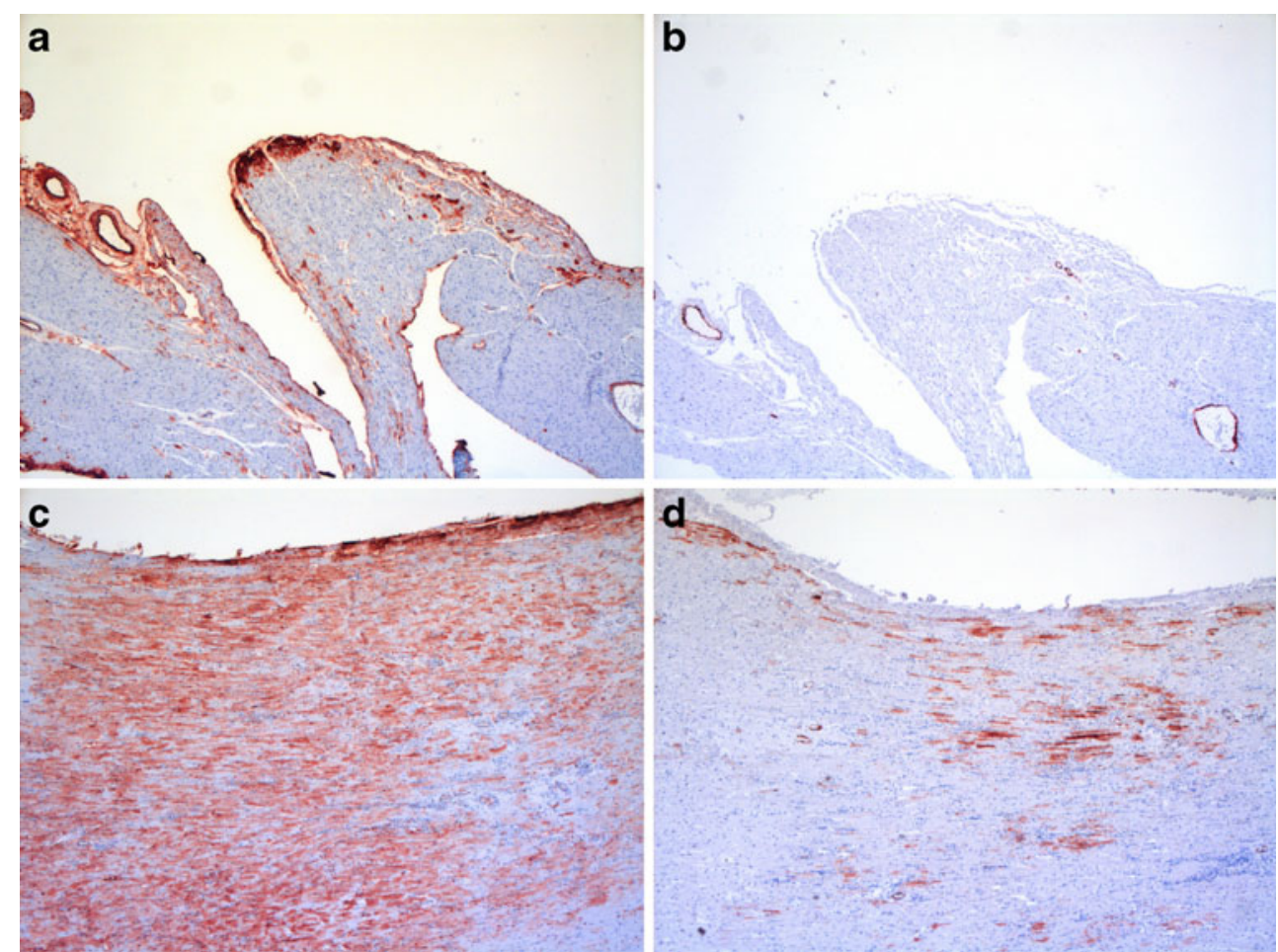

probably shorter than in cases of myocardial infarctions; for this reason, the terminal complement complex is positive only in this last group.

Particularly interesting is the expression pattern of fibronectin in $\mathrm{CO}$ intoxications compared to the other groups: in the intoxications in which necrosis occurred in both cardiac chambers, the right heart was prevalently more affected than the left, as shown by the positive $\Delta$ values. In groups 2 and 3, if necroses were detected in both ventricles, they were similarly distributed in both cardiac chambers or prevalent at the left one. We observed this phenomenon in cases of severe pulmonary fat embolism and pulmonary thromboembolism $[22,23]$ compared to controls. Similarly, also in cases of $\mathrm{CO}$ intoxications, the most important
Fig. 3 Hanging (Table 3, case 5). a Fibronectin, RV, grade 0 . b C5b-9, RV, grade 0 . c Fibronectin, $\mathrm{LV}$, grade 1 . d C5b-9, LV, Grade 0. $\Delta$ Fibronectin $=-1, \Delta \mathrm{C} 5 \mathrm{~b}-9=0$
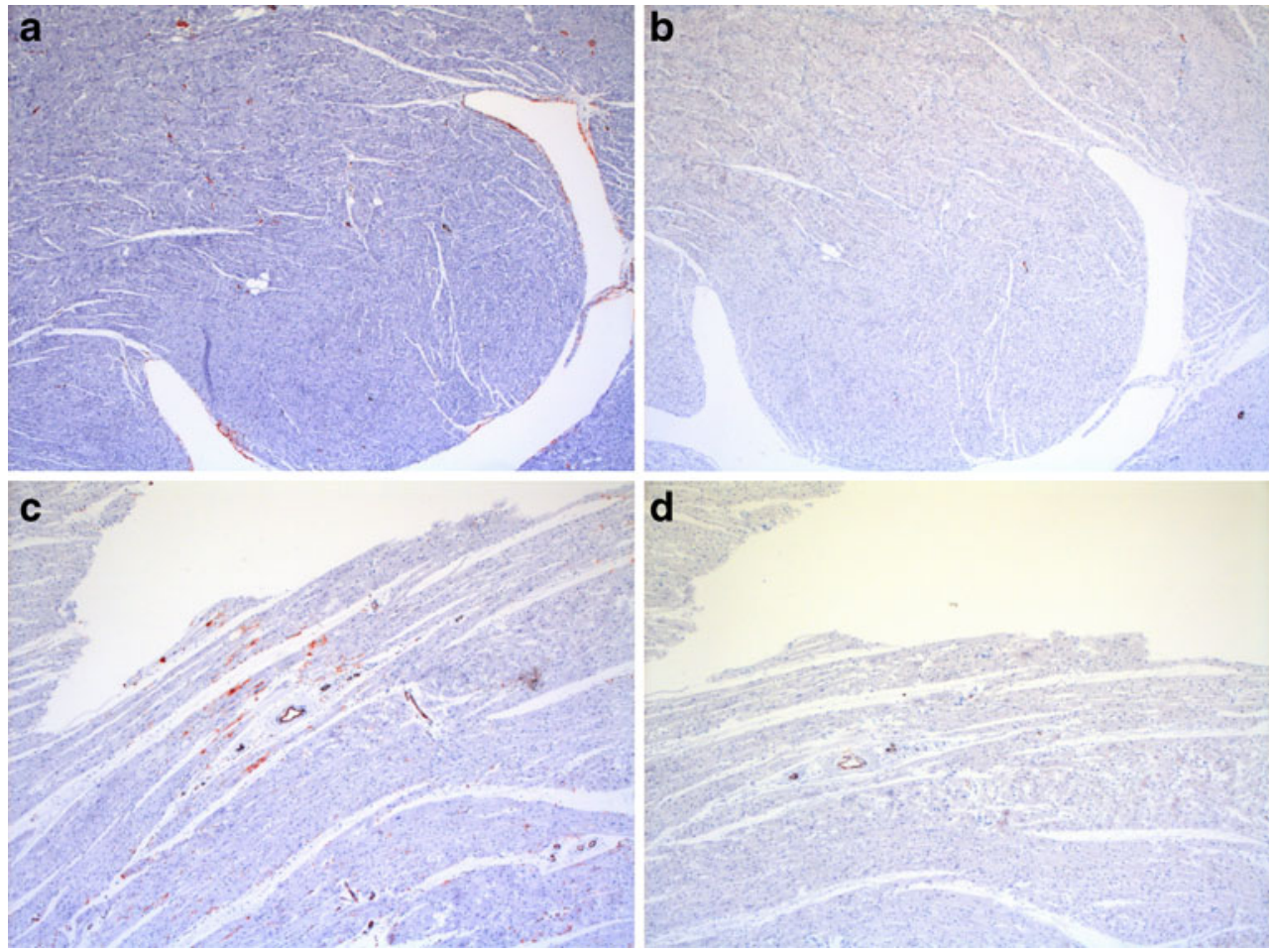
Table 4 Expression of Fibronectin at different cardiac regions in 13 cases of $\mathrm{CO}$ intoxications

\begin{tabular}{cccccc}
\hline ID & RV & LV S & LV AW & LV LW & LV PW \\
\hline 14 & 2 & 2 & 0 & 0 & 1 \\
15 & 2 & 1 & 1 & 1 & 1 \\
16 & 1 & 0 & 1 & 1 & 1 \\
17 & 2 & 2 & 2 & 2 & 2 \\
18 & 3 & 1 & 1 & 1 & 2 \\
19 & 2 & 1 & 2 & 2 & 2 \\
20 & 2 & 1 & 1 & 1 & 1 \\
21 & 3 & 2 & 2 & 2 & 2 \\
22 & 2 & 0 & 1 & 1 & 2 \\
23 & 3 & 1 & 2 & 2 & 2 \\
24 & 2 & 1 & 1 & 1 & 0 \\
25 & 3 & 2 & 2 & 1 & 2 \\
26 & 3 & 1 & 2 & 2 & 2 \\
\hline
\end{tabular}

The expression at the RV was significantly higher if compared to each region of the LV. The distribution at the different regions of the LV was similar

$R V$ right ventricle, $L V$ left ventricle, $A W$ anterior wall, $L W$ lateral wall, $P W$ posterior wall

parameter to evaluate the degree of the involvement of the cardiac chambers is to compare the extension of the damage in both ventricles. If only the extension of the damage at the right ventricle is taken into account, no differences can be evidenced between the study group and the myocardial infarctions. On the contrary, the comparison of the left ventricles only shows a minor involvement of this chamber in the study group.

For what concerns the distribution of the immunoreactions, the damage was prevalently observed at the subendocardial region in cases of hanging. Also in cases of CO intoxications, the subendocardial region was the most affected, but the damage tended to be much more diffuse at the inner $2 / 3$ of the right wall. In cases of heart infarction transmural damage was often observed.

The predominant attention paid in the past to the pathology of left ventricle to the detriment of the right one may explain the substantial missed detection of pathological changes at the right ventricle. Indeed, when investigated, a peculiar involvement of the right ventricle in cases of monoxide intoxications was detected: Lindenberg [24] described a marked dilatation of right ventricle and even a predominance of histological lesions at the right ventricle in an animal model as well as in several humans. In a large series of clinical cases treated for moderate to severe $\mathrm{CO}$ poisoning Satran et al. [7] described right ventricular dysfunction at echocardiography in 34\% of the patients. In our series, the right ventricle was prevalently damaged in $54 \%$ of the cases. A possible explanation for this difference may be the higher $\mathrm{COHb}$ levels in our series (mean $53.7 \%$, min. 54\%, max. 75\%) compared to that clinical study (mean 33.1\%, min. 2\%, max. 65\%). In addition, the sensibility of the diagnostic methods is different: from a functional point of view, the activity of the right ventricle may be normal even in presence of cardiac damage detectable at histology, at least in an early phase.

The right ventricle has a better tolerance to global hypoxia than the left one because of the minor oxygen demand and a better coronary perfusion during both systole and diastole $[25,26]$. Our observations in cases of hanging seem to confirm these statements: the right ventricle was never more affected than the left one and in four cases fresh cardiac damage prevailed at the left ventricle. Only in a minor number of cases of hanging, an immediate cessation of the cardiac activity occurs probably because of the stimulation of the vagal nerve [27]. Usually, cardiac activity is detectable for some minutes (7-18 min or even longer according to [27]) after hanging. During this time, hypoxic cardiac changes can occur.

Typically, the function of the right ventricle is compromised when the impendance to right ventricular ejection is acutely increased as it happens in cases of pulmonary embolism $[24,25]$. If pulmonary hypertension persists, a discrepancy between augmented oxygen demand of the right ventricle and diminished coronary flow occurs, leading to right ventricular ischemia and right heart failure [19].

Some investigators suggested that $\mathrm{CO}$ promotes endothelium-dependent vasoconstriction by inhibiting NO production [28] at vascular level. This is especially true for exogenous CO, as in cases of intoxication [29]. Moreover, carbon monoxide determines a cardiac inotropic effect with augmented oxygen demand and diminished coronary perfusion, a situation that can rapidly precipitate toward cardiac ischemia [30]. An increase of the pulmonary pressure was reported in cases of $\mathrm{CO}$ poisoning [31, 32], possibly as a consequence of the severe cerebral hypoxia following intoxication [33, 34].

The hypothesis of a prevalent ischemic right ventricular damage following pulmonary hypertension in the study group is only apparently incompatible with the comparison with the group of myocardial infarctions. The vast majority of the heart infarctions are in fact characterised by the primary involvement of the left ventricle. In fatal cases, however, the terminal failure of the right ventricle always occurs [35] so that fresh lesions at this chamber are common but basically less extended than those at the left ventricle [19]. Similarly, in cases of primary ischemic lesions at the right ventricle following pulmonary hypertension, lesion of the left ventricle also occur; however, the damage is prevalently detectable at the right chamber.

This study demonstrates the presence of fresh cardiac damage prevalently localised at the right ventricle in cases of fatal CO poisoning. Data from the literature suggest a 
possible ischemic nature of this damage following pulmonary hypertension. The reaction pattern of the antibody fibronectin seems to confirm this theory. Global hypoxia, which is present in both $\mathrm{CO}$ intoxications and cases of hanging, does not explain the different distribution of the cardiac damage in these groups: in cases of hanging fresh necrosis is similarly distributed in both ventricles, while in $\mathrm{CO}$ intoxications fresh damage prevails at the right ventricle. The prevalent localisation of the fresh necrosis at the right ventricle is similar to what we observed in cases of fatal right ventricular failure following right ventricular ischemia in cases of severe fat embolism and pulmonary thromboembolism

We propose that in cases of $\mathrm{CO}$ poisoning, fresh cardiac damage occurs prevalently at the right ventricle and may be explained by ischemic changes following acute pulmonary hypertension.

\section{References}

1. Haldane J (1972) Medicolegal contribution of historical interest. The action of carbonic oxide on man. Forensic Sci 1:451-483

2. Bowen DA, Duffy P, Callear A, Fitton A (1989) Carbon monoxide poisoning. Forensic Sci Int 41:163-168

3. Prockop LD, Chichkova RI (2007) Carbon monoxide intoxication: an updated review. J Neurol Sci 262:122-130

4. Lin H, McGrath JJ (1989) Responses of the working rat heart to carbon monoxide. Physiol Behav 46:81-84

5. Chance B, Erecinska M, Wagner M (1970) Mitochondrial responses to carbon monoxide toxicity. Ann NY Acad Sci 174:193-204

6. Stearns WH, Drinker CK, Shaughnessy TJ (1938) The electrocardiographic changes found in cases of carbon monoxide (illuminating gas) poisoning. Am Heart J 15:434-447

7. Middleton GD, Ashby DW, Clark F (1961) Delayed and longlasting electrocardiographic changes in carbon-monoxide poisoning. Lancet 1:12-14

8. Shafer N, Smilay MG, MacMillan FP (1965) Primary myocardial disease in man resulting from acute carbon monoxide poisoning. Am J Med 38:316-320

9. Satran D, Henry CR, Adkinson C, Nicholson CI, Bracha Y, Henry TD (2005) Cardiovascular manifestations of moderate to severe carbon monoxide poisoning. JACC 45:1513-1516

10. Klebs E (1865) Über die Wirkung des Kohlenoxyds auf den thierische Organismus. Virchow's Arch Path Anat 32:450-517

11. Ehrich WE, Lewey FH (1944) Cardiac changes from CO poisoning. Am J Med Sci 208:511-523

12. Klavis G, Schulz LC (1966) Herzschaden bei der akuten Kohlenmonoxyd-Vergiftung. Arch Toxikol 21:250-260

13. Marek Z, Piejko M (1972) Circulatory failure in acute carbon monoxide poisoning. Forensic Sci 1:419-425

14. Fineschi V, Agricola E, Baroldi G, Bruni G, Cerretani D, Mondillo S, Parolini M, Turillazzi E (2000) Myocardial findings in fatal carbon monoxide poisoning: a human and experimental morphometric study. Int J Leg Med 113:276-282

15. Maehly AC (1962) Quantitative determination of carbon monoxide. In: Lundquist F (ed) Methods of forensic science, vol 1. Interscience, New York, pp 539-593
16. Brinkmann B (1999) Harmonisation of medico-legal autopsy rules. Committee of Ministers. Council of Europe. Int J Leg Med 113:1-14

17. Brinkmann B, Sepulchre MA, Fechner G (1993) The application of selected histochemical and immunohistochemical markers and procedures to the diagnosis of early myocardial damage. Int J Leg Med 106:135-141

18. Ortmann C, Pfeiffer H, Brinkmann B (2000) A comparative study on the immunohistochemical detection of early myocardial damage. Int J Leg Med 113:215-220

19. Thomsen H, Held H (1995) Immunohistochemical detection of C5b-9 $(\mathrm{m})$ in myocardium: an aid in distinguishing infarctioninduced ischemic heart muscle necrosis from other forms of lethal myocardial injury. Forensic Sci Int 71:87-95

20. Ortmann C, Pfeiffer H, Brinkmann B (2001) Immunohistochemical alterations after intravital and post-mortem traumatic myocardial damage. Int J Leg Med 115:23-28

21. Edston E (1997) Evaluation of agonal artifacts in the myocardium using a combination of histological stains and immunohistochemistry. Am J Forensic Med Pathol 18:163-167

22. Fracasso T, Karger B, Pfeiffer H, Sauerland C, Schmeling A (2010) Immunohistochemical identification of prevalent right ventricular ischemia causing right heart failure in cases of pulmonary fat embolism. Int J Legal Med doi:10.1007/s00414-009-0382-3

23. Fracasso T, Pfeiffer H, Sauerland C, Schmeling A (2010) Morphological identification of right ventricular failure in cases of fatal pulmonary thromboembolism. Int $\mathrm{J}$ Legal Med doi:10.1007/s00414-010-0486-9

24. Lindenberg R (1963) Patterns of CNS vulnerability in acute hypoxaemia, including anesthesia accidents. In: Schadé JP, Mc Menemey WH (eds) Selective vulnerability of the brain in hypoxaemia. Blackwell, Oxford, pp 189-209

25. Gold FL, Bache RJ (1982) Transmural right ventricular blood flow during acute pulmonary artery hypertension in the sedated dog. Circ Res 51:196-204

26. Lowensohn HS, Khouri EM, Gregg DE, Pyle RL, Patterson RE (1976) Phasic right coronary artery blood flow in conscious dogs with normal and elevated right ventricular pressures. Circ Res 39:760-766

27. Miloslavich E (1919) Zur Lehre vom Erhängungstode. Vierteljahresschrift gerichtl offentl Med 58:162-168

28. Li Volti G, Vanella L, Gazzolo D, Galvano F (2008) Carbon monoxide: vasoconstrictor or vasodilator? That's the question. Am J Physiol Ren Physiol 295:F901-F903

29. Lamon BD, Zhang FF, Puri N, Brodsky V, Goligorsky MS, Nasjletti A (2009) Dual pathway of carbon monoxide-mediated vasoregulation. Circ Res 105:775-783

30. Wattel F, Favory R, Lancel S, Neviere R, Mathieu D (2006) Monoxyde de carbone et cour: des effets univoques? Bull Acad Natl Méd 190:1961-1975

31. Bergofski EH, Bass BG, Ferretti R, Fishman A (1963) Pulmonary vasoconstriction in response to precapillary hypoxemia. J Clin Invest 42:1201-1215

32. Theissen JL, Loick HM, Traber LD, Herndon DN, Traber DL (1992) Carbon monoxide and pulmonary circulation in an ovine model. J Burn Care Rehabil 13:623-627

33. Naeije R, Peretz A, Cornil A (1980) Acute pulmonary edema following carbon monoxide poisoning. Intensive Care Med 6:189-191

34. Zhuang J, Xu F, Campen M, Hernandez J, Shi S, Wang R (2006) Transient carbon monoxide inhibits the ventilatory responses to hypoxia through peripheral mechanisms in the rat. Life Sci 78:2654-2661

35. Barnard D, Alpert JS (1987) Right ventricular function in health and disease. Curr Probl Cardiol 12:423-449 